\title{
Suicidal ideation and associated factors among school-going adolescents in rural Ghana
}

\author{
Emmanuel Nii-Boye Quarshie ${ }^{1,2,3}$ (D) $\cdot$ Samuel Kofi Odame ${ }^{4}$ (i)
}

Accepted: 14 January 2021 / Published online: 9 February 2021

(C) The Author(s) 2021

\begin{abstract}
Suicidal ideation is a critical risk for attempted suicide and eventual suicide. Little is known about suicidal ideation among rural adolescents in most sub-Saharan African countries. We aimed to estimate the 12-month prevalence of suicidal ideation and to describe some of the common and gender-specific associated factors among in-school adolescents in rural Ghana. We conducted a cross-sectional survey involving a random sample of 1101 in-school adolescents aged 10-19 years in a rural district in Eastern Ghana. The Suicidal Behavior Questionnaire-Revised was used to assess suicidal ideation. Overall, 25.1\% participants (95\% $\mathrm{CI}=22.5-27.7)$, representing $28.3 \%$ females $(95 \% \mathrm{CI}=24.7-32.2)$ and $21.5 \%$ males $(95 \% \mathrm{CI}=18.0-25.2)$ reported suicidal ideation during the previous 12 months. Females who experienced personal and interpersonal adversities mainly outside the family context were likely to report suicidal ideation, while suicidal ideation among males was associated with conflict with parents. Regardless of gender, adolescents who reported exposure to a friend's attempted suicide were about two times more likely to report suicidal ideation. The prevalence of suicidal ideation among adolescents in rural Ghana compares with in-school estimates from other countries within sub-Saharan Africa, but also underscores the need for targeted and universal prevention programmes and intervention efforts to mitigate the potential transition from suicidal ideations to suicidal attempts and eventual deaths by suicide among rural adolescents.
\end{abstract}

Keywords Adolescents $\cdot$ Ghana $\cdot$ In-school adolescents $\cdot$ Suicide $\cdot$ Suicidal ideation $\cdot$ Rural adolescents

\section{Introduction}

Recent evidence suggests that, globally, about 3.8 per 100,000 persons aged 10-19 die by suicide annually (Glenn et al., 2020). In sub-Sahara Africa, suicide remains in the 12 leading causes of death among young people aged 10-24 (Naghavi \& Global Burden of Disease Self-Harm Collaborators, 2019). Besides suicidal planning and suicidal attempt, evidence by the World Health Organisation (WHO) and the recent growing body of literature have identified suicidal ideation to be

Emmanuel Nii-Boye Quarshie

e.n.quarshie@1eeds.ac.uk; enquarshie@gmail.com

Samuel Kofi Odame

odamesamuelkofi@gmail.com

1 School of Psychology, University of Leeds, Lifton Place, Leeds, West Yorkshire LS2 9JT, UK

2 Department of Psychology, University of Ghana, Accra, Ghana

3 Centre for Suicide and Violence Research (CSVR), Accra, Ghana

4 Department of Sociology, University of Ghana, Accra, Ghana associated with elevated risk of suicide; across all age groups and gender, persons with a history of suicidal ideation are at an increased likelihood of death by suicide (Cha et al., 2018; Franklin et al., 2017; Glenn et al., 2020; Hawton, Saunders, \& O'Connor, 2012; Klonsky, May, \& Saffer, 2016; Turecki et al., 2019; WHO, 2014). This evidence warrants research attention on suicidal ideation, particularly, among vulnerable groups, including adolescents in rural and underserved communities within low- and middle-income countries (Hirsch, 2006; Hirsch \& Cukrowicz, 2014; Klonsky et al., 2016; McKinnon, Gariépy, Sentenac, \& Elgar, 2016; Nock, 2012; Uddin, Burton, Maple, Khan, \& Khan, 2019; WHO, 2014). Suicidal ideation has been defined as thinking about engaging in a suicide-related behaviour (Crosby, Ortega, \& Melanson, 2011; House, Kapur, \& Knipe, 2020; Klonsky et al., 2016; Turecki et al., 2019).

Evidence of systematic reviews and meta-analyses shows variations in national and regional prevalence estimates of suicidal ideation among adolescents (Aggarwal, Patton, Reavley, Sreenivasan, \& Berk, 2017; Lim et al., 2019; McKinnon et al., 2016; Uddin et al., 2019). The pooled 12-month prevalence estimates of suicidal ideation among adolescents have identified 
the highest estimate in Africa (20.6\%, 95\% confidence interval [CI]: 13.7-29.7\%), compared to the other regions of the world: South America (18.4\%, 95\% CI: 16.3-20.7\%), Europe (16.3\%, 95\% CI: $15.3-17.5 \%)$, Asia (13.3\%, 95\% CI: $10.9-16.3 \%)$, and North America (12.8\%, 95\% CI: 6.4-24.1\%) (Lim et al., 2019).

Notably, however, most of the primary studies providing evidence for these systematic reviews and meta-analyses have been conducted with in-school adolescents in urban areas (Lim et al., 2019; McKinnon et al., 2016; Quarshie, Waterman, \& House, 2020c; Uddin et al., 2019). As can be said generally about the mental health of rural-dwelling young people (Kelleher, Taylor, \& Rickert, 1992), suicidal behaviour among rural-dwelling adolescents in African countries has received less research attention (Hirsch, 2006; Hirsch \& Cukrowicz, 2014; Kabiru, Izugbara, \& Beguy, 2013; Kabiru, Undie, \& Ezeh, 2011; Quarshie, Waterman, \& House, 2020c). A systematic search for literature from Africa ${ }^{1}$ to contextualise the current study found only four published primary studies reporting evidence on suicidal ideation, specifically, among rural adolescents in six countries within sub-Saharan Africa: Burkina Faso, Ethiopia, Ghana, Tanzania (Nyundo et al., 2020), South Africa (Shilubane et al., 2014), and Uganda (Kinyanda, Kizza, Levin, Ndyanabangi, \& Abbo, 2011; Nyundo et al., 2020; Rudatsikira, Muula, Siziya, \& Twa-Twa, 2007). The 12month prevalence estimates of suicidal ideation vary within and across each of these countries: Burkina Faso (1.2\%), Ethiopia $(6.1 \%-10.2 \%)$, Ghana $(4.0 \%)$, Tanzania $(4.6 \%)$, and Uganda $(1.5 \%-22.0 \%)$.

The socio-ecological framework has been recommended by the WHO and leading researchers for the study of factors associated with suicidal behaviour ${ }^{2}$ (Shagle \& Barber, 1995; WHO, 2014); this framework has been found useful to understanding suicidal behaviour among adolescents (AyyashAbdo, 2002; Hirsch \& Cukrowicz, 2014; Perkins \& Hartless, 2002; Pfledderer, Burns, \& Brusseau, 2019). Notably, the socio-ecological framework has been applied variously to the understanding and promotion of pro-health behaviours and the prevention of negative health behaviours and outcomes (Centers for Disease Control and Prevention, 2019). The framework suggests that health behaviours and outcomes are influenced by multilevel factors existing at the

\footnotetext{
${ }^{1}$ We searched MEDLINE, PsycINFO, African Journals OnLine, and African Index Medicus up to January 2020, using keywords [e.g., ("suicide ideation" OR "suicidal ideation" OR "self-harm ideation" OR suicide* OR self-injur* OR mental) AND ("rural adolescents" OR "rural dwelling adolescents" OR Adolescen* OR Child* OR Students OR Teen* OR "Young adults" OR youth OR pupils)]. We did not apply any language restrictions. Our geographic search filter to identify countries in Africa included names of the countries in both English and languages relevant to the countries. We supplemented the searches by reviewing references and forward citations of relevant articles.

${ }^{2}$ Suicidal behaviour is taken to mean "a range of behaviours that include thinking about suicide (or ideation), planning for suicide, attempting suicide and suicide itself' (p.12). WHO. (2014). Preventing suicide: A global imperative. Geneva, Switzerland: WHO.
}

individual, relationship, community and societal levels (Centers for Disease Control and Prevention, 2019). In terms of suicidal behaviour, the socio-ecological framework suggests that the associated risk factors vary widely, including personal histories, lifestyle and health circumstances, social and cultural factors, and policy factors (Pfledderer et al., 2019). In other words, suicidal behaviour results from the interplay among many factors at multiple layers of an individual's proximal and distal environment (Ayyash-Abdo, 2002; Perkins \& Hartless, 2002; Shagle \& Barber, 1995; WHO, 2014). Specifically, available evidence from sub-Saharan Africa suggests female gender, psychological problems (including worry, loneliness, depression, and anxiety), bullying victimisation, alcohol use, exposure to violence, exposure to war trauma, being a younger adolescent, being an orphan, financial problems, sexual abuse, and intimate partner violence victimisation as factors associated with increased odds of suicidal ideation among rural adolescents (Kinyanda et al., 2011; Nyundo et al., 2020; Rudatsikira et al., 2007; Shilubane et al., 2014). However, social support, and living with both parents are associated with reduced chances of suicidal ideation (Nyundo et al., 2020; Shilubane et al., 2014).

\section{Aims of the Study}

It is noteworthy that the only available (household-based crosssectional) study reporting evidence on suicidal ideation among rural adolescents in Ghana was conducted in Ningo Prampram (Nyundo et al., 2020), a peri-urban community in the Greater Accra Region (Ghana Statistical Service - GSS, 2013). Thus, the current study sought to provide evidence from rural-dwelling adolescents in Eastern Ghana. Specifically, we aimed to:

i. Estimate the 12-month prevalence of suicidal ideation among school-attending adolescents ${ }^{3}$ in rural Ghana.

ii. Identify the differences and commonalities in gender, personal factors, and social adversities associated with suicidal ideation among school-attending adolescents in rural Ghana.

\section{Materials and Methods}

We followed Strengthening the Reporting of Observational Studies in Epidemiology (STROBE) recommendations for cross-sectional study, to design, conduct, and report this study (Von Elm et al., 2007).

\footnotetext{
${ }^{3}$ Based on the definition by the WHO (2009), we used the term "adolescents" to denote individuals between 10 and 19 years. WHO. (2009). Strengthening the health sector response to adolescent health and development. Geneva, Switzerland: WHO.
} 


\section{Design, Setting, and Participants}

Considering that this study is part of a larger study from Ghana, detailed information about the methods used has been reported elsewhere (Odame, Quarshie, Oti-Boadi, AndohArthur, \& Asante, 2020). We conducted a cross-sectional survey involving Junior High School ${ }^{4}$ (JHS) adolescents in the Ayensuano rural district in the eastern region of Ghana (Ghana Statistical Service, 2014), using a self-report anonymous questionnaire. We obtained the list of schools and pupil statistics from the District Educational Directorate of Ayensuano. We predetermined a minimum sample size of 971 students, using Cochran's formula for calculating a sample size for proportions (Cochran, 1963). However, we increased the predetermined sample size by $25 \%$ for two analytical reasons: to obtain satisfactory precision and confidence interval widths, and to compensate for nonresponse (Naing, Winn, \& Rusli, 2006). Figure 1 illustrates the participant recruitment process.

In all, we approached and invited 1214 students to respond to the survey, but 1101 (female $=575$; male $=526$ ) provided complete data included in the study - representing a response of rate of $90 \%$.

\section{Measures}

The participants responded to a self-report anonymous questionnaire composed of questions related to socio-demographic characteristics, personal lifestyle factors, social adversity, and suicidal ideation.

Socio-demographic Characteristics We included seven items to assess the socio-demographic backgrounds of the participants: age, gender (female or male), grade, living arrangement, caretaker's employment status, family structure (measured by father's number of wives), and romantic relationship status.

Outcome Variable Suicidal ideation was the main outcome variable, even though we also assessed suicidal behaviour risk. We used the 4-item Suicide Behavior QuestionnaireRevised [SBQ-R] (Osman et al., 2001) to assess the outcome variables. Suicidal ideation was assessed with the question, How often have you thought about killing yourself in the past year? The response ratings ranged from never $=1$, to very often (5 or more times) $=5$. Answers were transformed into dichotomous responses (presence vs. absence of suicidal ideation, for analysis). The other three items are Have you ever

\footnotetext{
${ }^{4}$ In Ghana, Junior High Schools are targeted at young people aged 1114 years, but due to delayed school enrolment in rural communities, typically, older and late adolescents aged 15-19 years are also predominantly found at this level of basic education in rural Ghana.
}

thought about or attempted to kill yourself?, Have you ever told someone that you were going to commit suicide, or that you might do it?, and How likely is it that you will attempt suicide someday? The three items have different response options: $1-4,1-3$, and $0-6$, respectively. The SBQ-R yields a total score between 3 and 18 points. For an adolescent sample, a total minimum score of 7 out of 18 is the cut-off $(\geq 7)$ indicating high suicidal behaviour risk, whereas a total score between 3 and 6 indicates low suicidal behaviour risk (Osman et al., 2001). Thus, in the current study, suicidal behaviour risk was binary, high suicidal behaviour risk vs. low suicidal behaviour risk. In Ghana, the SBQ-R has a satisfactory internal consistency (Cronbach's alpha $=0.78$ ) among both adolescents and adults (Adjorlolo, Anum, \& Amin, 2020; Quarshie, Cheataa-Plange, Annor, Asare-Doku, \& Lartey, 2019; Quarshie, Odame, \& Annor, 2020). The Cronbach's alpha score in the current study was 0.71 .

Exposure Variables We included eight binary (No or Yes) response-rated personal lifestyle factors and variables assessing the experience of social or interpersonal adversities, adopted from the 2012 WHO-Global School-based Student Health Survey questionnaire used in Ghana (Owusu, 2012). Notably, even though many of the variables were assessed using questions that solicited continuous or frequency-based responses, we binarised the responses (as shown in e-Table 1) to facilitate analysis and meaningful interpretations of results. These variables included: weekly alcohol use (In a typical week, how many times do you have at least on alcoholic drink?), truancy (During the past 12 months, how many days did you miss classes or school without permission?), bullying victimisation (During the past 12 months, how many days were you bullied?), and sexual abuse victimisation (Has anyone forced you [i.e. physically or verbally] to engage in sexual activities against your will?). Additionally, we adopted one item from the 5-item Duke University Religion Index (DUREL) (Koenig \& Büssing, 2010) to assess religious participation: How often do you attend church or other religious meetings?, with response options ranging from (1) never to (6) more than once per week. The supplementary material (e-Table 1) shows the variables included in this study and the specific questions used to assess them in the survey.

\section{Procedure}

The data collection took place between August 2019 and January 2020. The participants of the study were gathered in their school's assembly hall or a larger classroom designated for the survey, with sitting arrangement spaced by reasonable distance. After obtaining permission from the heads of the participating schools, informed consent of parents/guardians, and the participants' informed consent and assent, we gave each student a packet of the anonymous questionnaire to 
Fig. 1 Summary of participant recruitment process for self-report anonymous questionnaire survey
Junior High Schools (JHS) in Ayensuano rural district $(n=84)$

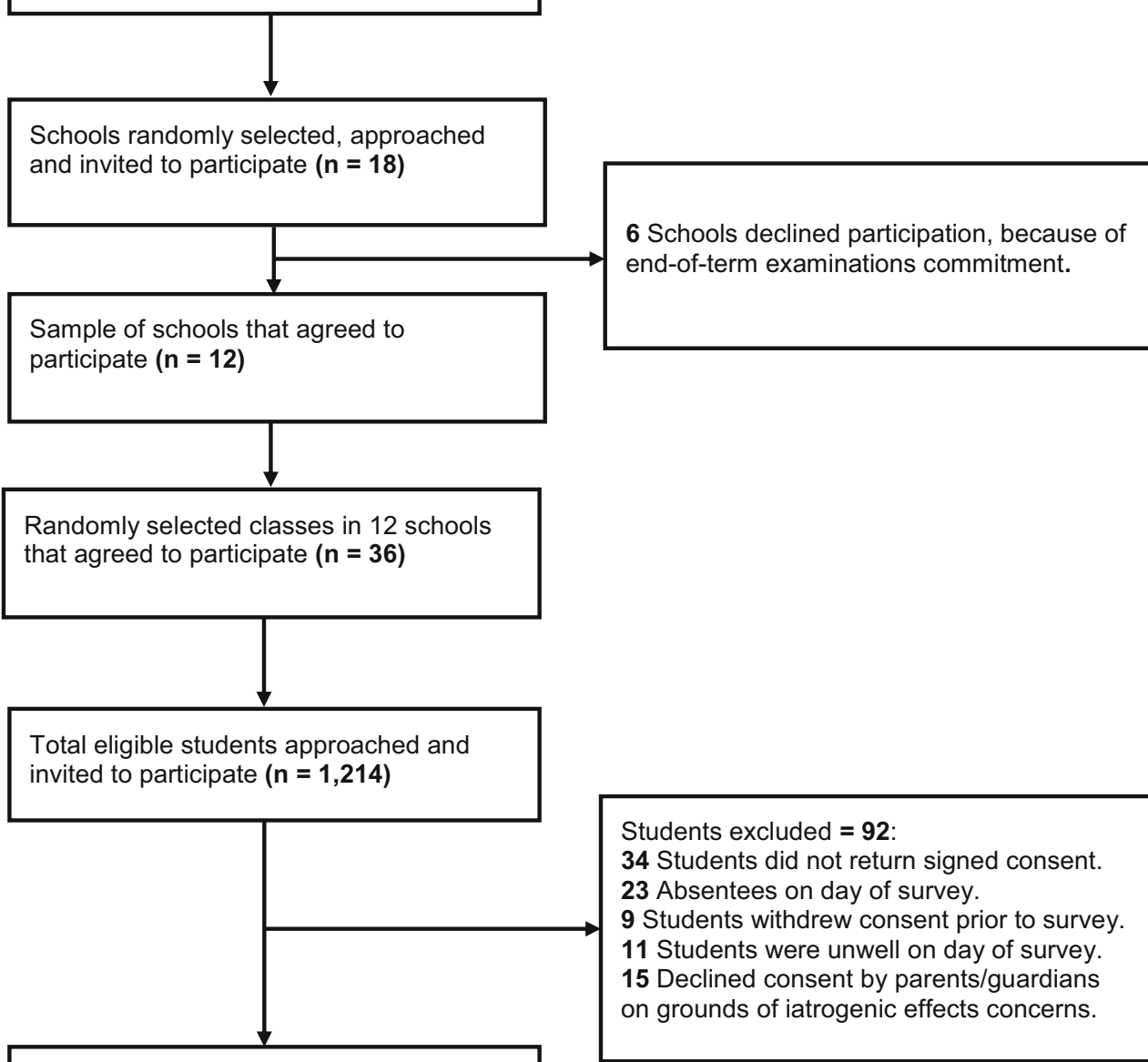

Total eligible students who consented to participate in survey $(n=1,122)$

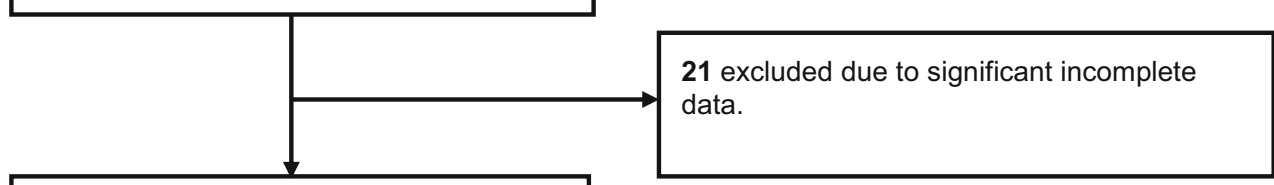

Students surveyed $(n=1,101)$

$($ Females $=\mathbf{5 7 5} ;$ Males $=\mathbf{5 2 6})$ answer. Averagely, the completion of the questionnaire lasted between 22 and $35 \mathrm{~min}$. Each student placed their answered questionnaire in an opaque box at the exit door.

\section{Data Analysis}

We used the Statistical Package for Social Sciences (SPSS version 26.0 for Windows) to analyse the data. Suicidal ideation was the outcome variable in the main statistical analysis, while the exposure variables or correlates comprised personal factors and the variables of social or interpersonal adversity specified. The socio-demographic variables were included in the statistical modelling as covariates. As the loss of cases due to missing data was less than $5 \%$, we used the list-wise deletion of missing data strategy (Graham, 2012). The coding of the variables included in the statistical analysis are shown in the supplementary material (e-Table 1). The data analysis proceeded in three stages; at each stage, we stratified the data by gender (female and male), guided by the aims of the study. Firstly, we performed descriptive analysis of the data by applying frequencies and proportions to assess the distribution of the participants across the socio-demographic variables and the 12-month prevalence estimates of suicidal ideation and suicidal behaviour risk. Secondly, given the categorical nature of the data, we applied the Pearson's Chi-square test $(\chi 2)$ to explore the bivariate relationships between of 12 -month 
suicidal ideation and each of the socio-demographic variables, personal factors and the variables of social adversity specified. We performed point-biserial correlation $\left(r_{\mathrm{pb}}\right)$ tests (Prematunga, 2012) to examine the possible bivariate relationship between religious participation and 12-month suicidal ideation. Statistically significant results were determined using the $p$ value less than $0.05(p<0.05)$. Thirdly, we performed a multivariable logistic regression analysis, to examine the possible associations between the binary outcome variable (12-month suicidal ideation: No or Yes) and the specified correlates (personal factors, and variables of social adversity) and covariates (socio-demographic variables). We developed three models, one each for the overall sample, female adolescent sub-sample, and the male adolescent sub-sample. As recommended by leading statistical methodologists, the candidate correlates and covariates were entered in the multivariable logistic regression models regardless of the statistical significance of their bivariate relationships with the outcome variable (Babyak, 2004; Sun, Shook, \& Kay, 1996). We reported the results of the logistic regression as odds ratios with $95 \%$ confidence intervals $(\mathrm{CI})$ and associated $p$ values.

\section{Ethics}

This study was approved by the Department of Psychology Research Ethics Committee, University of Ghana, Accra. We followed the ethical procedures of the Ghana Education Service for conducting research involving pupils in basic educational institutions in Ghana. The Ayensuano District Educational Directorate in Eastern Ghana, and heads of all the participating schools permitted this study. Each participant signed a written consent form prior to responding to the survey; parents/guardians of underage participants provided consent and we obtained the assent of participants aged 1017 years, prior to taking part in the study.

\section{Results}

\section{Sample Characteristics}

Table 1 shows the socio-demographic characteristics of the participants, stratified by gender. The participants in this study $(n=1101)$ were aged $10-19$ years $($ mean $=15.3$; modal $=16$; $\mathrm{SD}=1.9)$; and $575(52.2 \%)$ were females.

Most of the participants were older adolescents $(53.1 \%)$, in JHS $1(64.3 \%)$ and had a caretaker who was employed $(89.5 \%)$. Most of the participants identified their family as monogamous - their father had one wife $(63.8 \%)$. More females $(n=270)$ than males $(n=199)$ self-identified as being in a romantic relationship $\left(\chi_{(1)}^{2}=9.35, p=0.002\right)$.

\section{Prevalence Estimates of Suicidal Ideation and Suicidal Behaviour Risk}

Overall, $276(25.1 \%$; 95\% CI = 22.5-27.7) participants reported suicidal ideation during the previous 12 months. As shown in Table 2, more females $(n=163 ; 28.3 \%$; 95\% CI $=24.7-32.2)$ than males $(n=113 ; 21.5 \% ; 95 \% \mathrm{CI}=18.0-25.2)$, and more younger adolescents $(n=167 ; 32.4 \% ; 95 \% \mathrm{CI}=28.3-36.6)$ than older adolescents $(n=109 ; 18.6 \%$; 95\% CI $=15.5-22.0)$ reported suicidal ideation during the previous 12 months.

Based on the SBQ-R binary categorisation of suicidal behaviour risk, overall, $18 \%(n=198)$ of the participants were at a high risk of suicidal behaviour (female $=20.0 \%[n=115]$; male $=15.8 \%[n=83]$; younger adolescents $=21.7 \%[n=$ $112]$; older adolescents $=14.7 \%[n=86])-$ an indication that these participants might need further clinical assessment or mental health referral.

\section{Bivariate Associations}

As shown in Table 2, overall, the bivariate analysis showed statistically significant associations between most of the socio-demographic variables, personal factors and social adversities included, but social adversities showed the strongest bivariate associations.

Overall, regardless of gender, sexual abuse victimisation $\left(\chi_{(1)}^{2}=80.68, p<0.001\right)$, exposure to a friend's attempted suicide $\left(\chi_{(1)}^{2}=78.59, p<0.001\right)$, breakup $\left(\chi_{(1)}^{2}=35.43\right.$, $p<0.001)$, and schoolwork problems $\left(\chi_{(1)}^{2}=34.01\right.$, $p<0.001$ ) showed the strongest bivariate association with suicidal ideation during the previous 12 months. In terms of gender, conflict with parents $\left(\chi_{(1)}^{2}=37.7, p<0.001\right)$ showed a strong bivariate association with suicidal ideation among males, while breakup $\left(\chi_{(1)}^{2}=39.07, p<0.001\right)$ and weekly alcohol use $\left(\chi_{(1)}^{2}=22.74, p<0.001\right)$ showed a strong bivariate association with suicidal ideation among females.

Furthermore, across the overall sample, there was a statistically non-significant negative correlation between religious participation and suicidal ideation during the previous 12 months $\left(r_{\mathrm{pb}}=-0.031, n=1101, p=0.310\right)$. Similarly, when stratified by gender, there was no statistically significant association between religious participation and suicidal ideation among neither female $\left(r_{\mathrm{pb}}=-0.043, N=575, p=0.300\right)$ nor male $\left(r_{\mathrm{pb}}=-0.029, N=526, p=0.505\right)$ adolescents.

\section{Multivariable Associations}

Each of the final logistic regression models for the overall sample $\left(\chi^{2}{ }_{(\mathrm{df}=19)}=171.19, p<0.001\right)$, female subsample $\left(\chi^{2}(\mathrm{df}=18)=\right.$ $100.42, p<0.001)$ and the male subsample $\left(\chi^{2}(\mathrm{df}=18)=85.27\right.$, $p<0.001$ ) was statistically significant, accounting for satisfactory proportions of the variance in the overall sample (76.8\%), female subsample (75.8\%), and male subsample (79.8\%) - see Table 3. 
Table 1 Demographic characteristics of participants

\begin{tabular}{|c|c|c|c|c|}
\hline \multirow[t]{2}{*}{ Variable } & \multirow{2}{*}{$\begin{array}{l}\text { Total sample } \\
(\mathrm{N}=1101)\end{array}$} & \multicolumn{2}{|c|}{ Adolescent group } & \multirow[t]{2}{*}{ Statistic of gender difference } \\
\hline & & $\begin{array}{l}\text { Females } \\
(\mathrm{n}=575)\end{array}$ & $\begin{array}{l}\text { Males } \\
(n=526)\end{array}$ & \\
\hline & $\mathrm{n}(\%)$ & $\mathrm{n}(\%)$ & $\mathrm{n}(\%)$ & $\chi^{2}$ ( $p$ value) \\
\hline Age: & & & & $8.79(.003)$ \\
\hline Younger adolescents (10-15 years) & $516(46.9)$ & $294(51.1)$ & $222(42.2)$ & \\
\hline Older adolescents (16-19 years) & $585(53.1)$ & $281(48.9)$ & $304(57.8)$ & \\
\hline Grade: & & & & $7.13(.028)$ \\
\hline JHS 1 & $708(64.3)$ & $389(67.7)$ & $319(60.6)$ & \\
\hline JHS 2 & $279(25.3)$ & $127(22.1)$ & $152(28.9)$ & \\
\hline JHS 3 & $114(10.4)$ & $59(10.3)$ & $55(10.5)$ & \\
\hline Living arrangement: & & & & $0.31(.858)$ \\
\hline Live with both parents & $606(55)$ & $321(55.8)$ & $285(54.2)$ & \\
\hline Live with one parent & $336(30.5)$ & $172(29.9)$ & $164(31.2)$ & \\
\hline Live with no parents & $159(14.4)$ & $82(14.3)$ & $77(14.6)$ & \\
\hline Caretaker's employment status: & & & & $9.38(.002)$ \\
\hline Unemployed & $116(10.5)$ & $45(7.8)$ & $71(13.5)$ & \\
\hline Employed & $985(89.5)$ & $530(92.2)$ & $455(86.5)$ & \\
\hline Family structure: & & & & $2.04(.153)$ \\
\hline Father has 1 wife & $702(63.8)$ & $378(65.7)$ & $324(61.6)$ & \\
\hline Father has $>1$ wife & $399(36.2)$ & $197(34.3)$ & $202(38.4)$ & \\
\hline In romantic relationship: & & & & $9.35(.002)$ \\
\hline No & $632(57.4)$ & $305(53.0)$ & $327(62.2)$ & \\
\hline Yes & $469(42.6)$ & $270(47.0)$ & $199(37.8)$ & \\
\hline
\end{tabular}

$\chi^{2}=$ Chi square

\section{Factors Associated with Suicidal Ideation in Overall Sample}

As shown in Table 3, having been exposed to a friend's suicide attempt $(\mathrm{aOR}=2.17,95 \%$ CI 1.49, 3.14; $p<.001)$, experiencing schoolwork problems $(\mathrm{aOR}=1.72,95 \% \mathrm{CI}$ $1.22,2.40 ; p=.002)$, sexual abuse victimisation $(\mathrm{aOR}=$ $1.70,95 \%$ CI 1.19, 2.42; $p=.003)$, and being in a polygamous family - father having more one wife $(\mathrm{aOR}=1.45,95 \% \mathrm{CI}$ $1.05,2.01 ; p=.026)$ were significantly associated with increased odds of suicidal ideation during the previous 12 months. However, being an older adolescent $(\mathrm{aOR}=$ 0.52 , 95\% CI $0.38,0.70 ; \mathrm{p}<.001$ ) was associated with reduced odds of suicidal ideation.

\section{Gender Difference and Commonality in Factors Associated with Suicidal Ideation}

Among females, having been exposed to a friend's suicide attempt $(\mathrm{aOR}=1.98,95 \% \mathrm{CI} 1.19,3.27 ; p=.008)$, experiencing schoolwork problems $(\mathrm{aOR}=1.97,95 \%$ CI 1.24, 3.14; $p=.004)$, breakup $(\mathrm{aOR}=1.88,95 \%$ CI 1.17, 3.01; $p=.009)$, sexual abuse victimisation $(\mathrm{aOR}=1.82,95 \% \mathrm{CI}$ $1.12,2.96 ; p=.016)$, weekly alcohol use $(\mathrm{aOR}=1.65,95 \%$ CI $1.02,2.67 ; p=.043$ ), and being in a polygamous family father having more one wife $(\mathrm{aOR}=1.61,95 \% \mathrm{CI} 1.02,2.52$; $p=.040$ ) were significantly associated with increased odds of suicidal ideation during the previous 12 months. Being an older adolescent $(\mathrm{aOR}=0.59,95 \%$ CI $0.39,0.89 ; p=.012)$, however, was associated with reduced odds of suicidal ideation - see Table 3.

Table 3 also shows that among male adolescents, while exposure to friend suicide attempt $(\mathrm{aOR}=2.66,95 \% \mathrm{CI}$ $1.49,4.77 ; p=.001)$, and conflict with parents $(\mathrm{aOR}=1.91$, $95 \%$ CI 1.12, 3.26; $p=.018$ ) were associated with increased odds of suicidal ideation, being an older adolescent $(\mathrm{aOR}=$ $0.41,95 \%$ CI $0.26,0.67 ; p<.001$ ) was associated with reduced odds of suicidal ideation.

It is notable, thus, that across the overall sample and regardless of gender, having been exposed to a friend's suicide attempt appeared to be the strongest and only factor associated with the increased odds of suicidal ideation, while being an older adolescent emerged as the factor with a statistically significant association with reduced odds of suicidal ideation. 


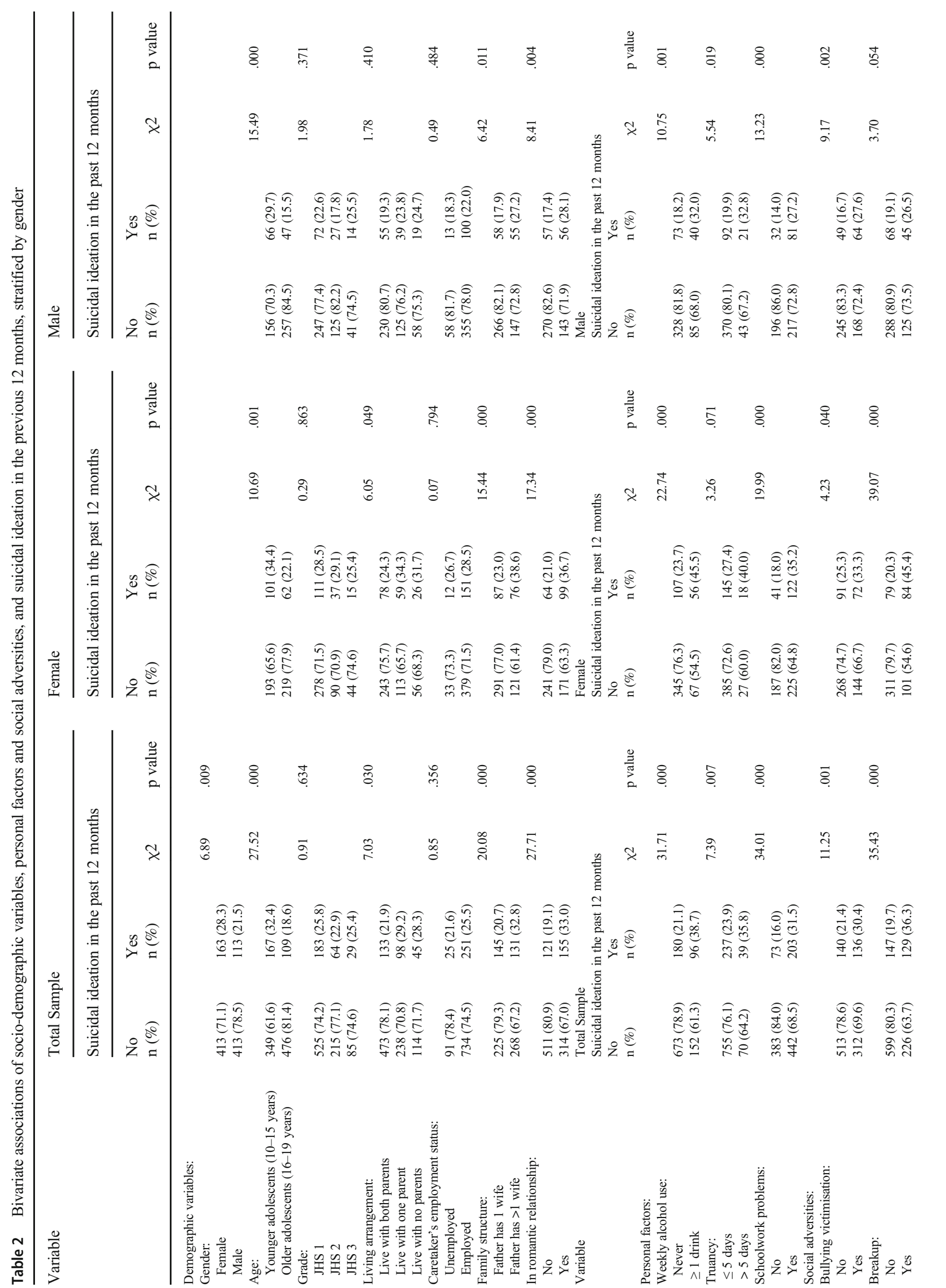




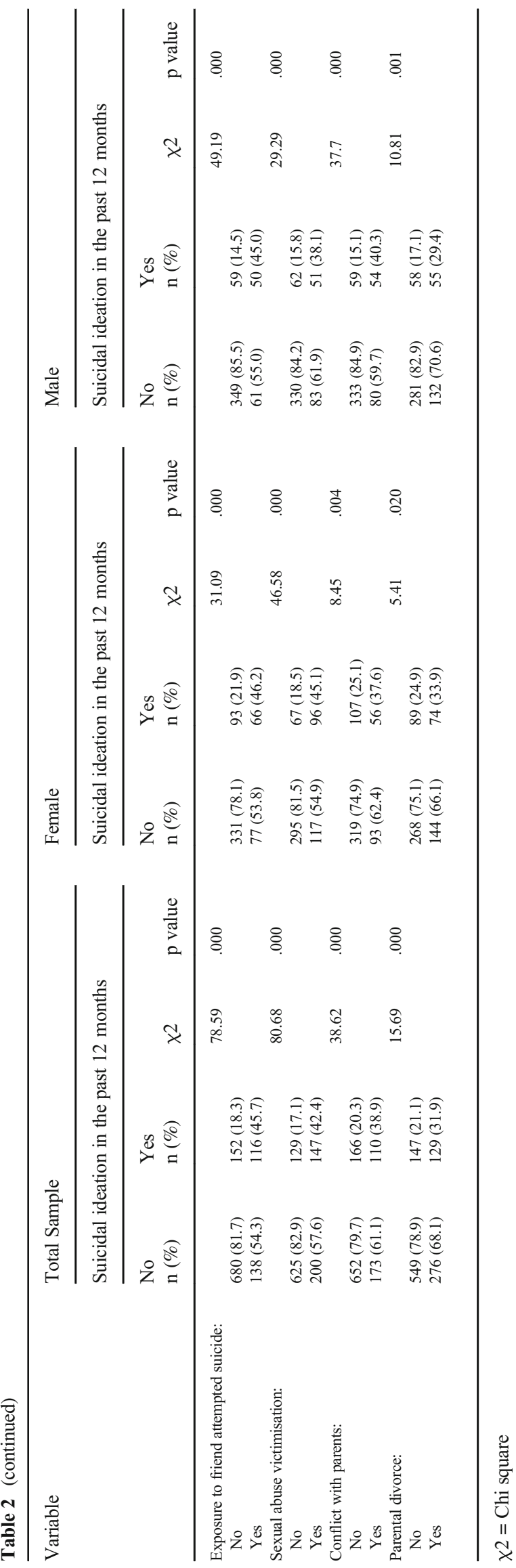

\section{Discussion}

This study has shown three key findings: 1) approximately 2.5 out of 10 adolescents (2.8 in 10 females; 2.1 in 10 males) reported suicidal ideation during the past 12 months; 2) female adolescents who experienced personal and interpersonal adversities outside the family were more likely to report suicidal ideation, while suicidal ideation among males was strongly associated with conflict with parents; and 3) regardless of gender, rural adolescents who reported being exposed to a friend's suicidal attempt were about three times more likely to report suicidal ideation, compared to those who did not report exposure to a friend's attempted suicide.

\section{Prevalence of Suicidal Ideation}

The overall 12-month prevalence estimate of suicidal ideation in the current study (25.1\%) is higher, compared to previous estimates from other rural contexts in sub-Saharan Africa (Kinyanda et al., 2011; Nyundo et al., 2020; Rudatsikira et al., 2007). This stark difference in estimates could be due to differences in methods (e.g., sampling and sample size, measures used etc.). As applied in the current study, nearly all the previous studies (Kinyanda et al., 2011; Nyundo et al., 2020; Rudatsikira et al., 2007) used a single-item measure to assess suicidal ideation. However, it must be clarified that the current study used a single-item contained in the multi-item scale of suicidal behaviour (SBQ-R) applied in the study; not a stand-alone single-item assessing suicidal ideation. Recent evidence suggests that the use of single-item measures could lead to misclassification of previous suicidal behaviour (Hom, Joiner Jr, \& Bernert, 2016; Millner, Lee, \& Nock, 2015). Interestingly, however, the estimates of the current study are comparable to those reported among in-school urban adolescents in Ghana (Asante, Kugbey, Osafo, Quarshie, \& Sarfo, 2017; Baiden et al., 2019) and other African countries (Lim et al., 2019; McKinnon et al., 2016; Uddin et al., 2019). As has been observed recently, probably, the precipitating factors of suicidal behaviour among in-school adolescents in Ghana may not be different between urban and rural school contexts; the general school climate (including peer relationships problems, unavailability of peer support, and bullying) could be presenting adolescents with increased risk of suicidal behaviour (Asante et al., 2017; Ohene, Johnson, Atunah-Jay, Owusu, \& Borowsky, 2015; Owusu, Hart, Oliver, \& Kang, 2011; Quarshie \& Andoh-Arthur, 2020). The finding that more female than male adolescents reported suicidal ideation is consistent with previous evidence (McKinnon et al., 2016; Page \& West, 2011; Uddin et al., 2019), and could be reflective of the general fact that girls are more likely to report internalising (mental) health problems than boys (Van Droogenbroeck, Spruyt, \& Keppens, 2018). 
Table 3 Multivariate associations of socio-demographic variables, personal factors and social adversities, and suicidal ideation in the previous 12 months, stratified by gender

\begin{tabular}{|c|c|c|c|c|c|c|c|c|c|c|c|c|}
\hline \multirow[b]{2}{*}{ Variables in models } & \multicolumn{4}{|c|}{ Model 1: Total sample $(\mathrm{n}=1101)$} & \multicolumn{4}{|c|}{ Model 2: Female $(\mathrm{n}=575)$} & \multicolumn{4}{|c|}{ Model 3: Male $(\mathrm{n}=526)$} \\
\hline & $\beta$ & $\mathrm{aOR}$ & $95 \% \mathrm{CI}$ & $\mathrm{p}$ value & $\beta$ & $\mathrm{aOR}$ & $95 \% \mathrm{CI}$ & $\mathrm{p}$ value & $\beta$ & $\mathrm{aOR}$ & $95 \% \mathrm{CI}$ & $\mathrm{p}$ value \\
\hline \multicolumn{13}{|l|}{ Demographic variables: } \\
\hline Gender & -0.25 & 0.78 & $0.57,1.06$ & .114 & & & & & & & & \\
\hline Age & -0.66 & 0.52 & $0.38,0.70$ & .000 & -0.53 & 0.59 & $0.39,0.89$ & .012 & -0.88 & 0.41 & $0.26,0.67$ & .000 \\
\hline \multicolumn{13}{|l|}{ Grade: } \\
\hline JHS 1 & \multicolumn{4}{|c|}{ Reference } & \multicolumn{4}{|c|}{ Reference } & \multicolumn{4}{|c|}{ Reference } \\
\hline JHS 2 & -0.09 & 0.91 & $0.63,1.32$ & .635 & 0.11 & 1.11 & $0.67,1.84$ & .671 & -0.23 & 0.79 & $0.45,1.39$ & .414 \\
\hline JHS 3 & -0.09 & 0.91 & $0.55,1.51$ & .721 & -0.38 & 0.69 & $0.34,1.39$ & .298 & 0.18 & 1.19 & $0.55,2.57$ & .653 \\
\hline \multicolumn{13}{|l|}{ Living arrangement: } \\
\hline Live with both parents & \multicolumn{4}{|c|}{ Reference } & \multicolumn{4}{|c|}{ Reference } & \multicolumn{4}{|c|}{ Reference } \\
\hline Live with one parent & 0.23 & 1.26 & $0.87,1.83$ & .224 & 0.39 & 1.48 & $0.89,2.46$ & .126 & -0.04 & 0.96 & $0.54,1.73$ & .903 \\
\hline Live with no parents & 0.14 & 1.15 & $0.73,1.81$ & .545 & 0.19 & 1.21 & $0.65,2.25$ & .547 & -0.07 & 0.93 & $0.46,1.89$ & .845 \\
\hline Caretaker's employment status & 0.16 & 1.17 & $0.70,1.95$ & .544 & -0.07 & 0.93 & $0.43,2.01$ & .849 & 0.45 & 1.57 & $0.77,3.19$ & .215 \\
\hline Family structure & 0.37 & 1.45 & $1.05,2.01$ & .026 & 0.47 & 1.61 & $1.02,2.52$ & .040 & 0.19 & 1.21 & $0.74,1.99$ & .444 \\
\hline In romantic relationship & 0.16 & 1.17 & $0.83,1.64$ & .366 & 0.08 & 1.09 & $0.69,1.71$ & .721 & 0.21 & 1.23 & $0.72,2.13$ & .449 \\
\hline \multicolumn{13}{|l|}{ Personal factors: } \\
\hline Religious participation & -0.03 & 0.97 & $0.88,1.08$ & .610 & -0.02 & 0.98 & $0.85,1.13$ & .773 & -0.04 & 0.96 & $0.82,1.12$ & .598 \\
\hline Weekly alcohol use & 0.32 & 1.38 & $0.97,1.96$ & .075 & 0.49 & 1.65 & $1.02,2.67$ & .043 & 0.19 & 1.21 & $0.69,2.14$ & .508 \\
\hline Truancy & 0.23 & 1.26 & $0.78,2.04$ & .340 & 0.24 & 1.27 & $0.62,2.61$ & .509 & 0.15 & 1.16 & $0.57,2.34$ & .677 \\
\hline Schoolwork problems & 0.54 & 1.72 & $1.22,2.40$ & .002 & 0.68 & 1.97 & $1.24,3.14$ & .004 & 0.45 & 1.57 & $0.93,2.65$ & .089 \\
\hline \multicolumn{13}{|l|}{ Social adversities: } \\
\hline Bullying victimisation & -0.04 & 0.96 & $0.69,1.32$ & .794 & -0.22 & 0.80 & $0.51,1.25$ & .331 & 0.05 & 1.05 & $0.64,1.73$ & .846 \\
\hline Breakup & 0.29 & 1.34 & $0.95,1.89$ & .092 & 0.63 & 1.88 & $1.17,3.01$ & .009 & -0.09 & 0.91 & $0.53,1.56$ & .720 \\
\hline Exposure to friend suicide attempt & 0.77 & 2.17 & $1.49,3.14$ & .000 & 0.68 & 1.98 & $1.19,3.27$ & .008 & 0.98 & 2.66 & $1.49,4.77$ & .001 \\
\hline Sexual abuse victimisation & 0.53 & 1.70 & $1.19,2.42$ & .003 & 0.59 & 1.82 & $1.12,2.96$ & .016 & 0.34 & 1.41 & $0.80,2.47$ & .232 \\
\hline Conflict with parents & 0.25 & 1.29 & $0.90,1.85$ & .164 & -0.10 & 0.90 & $0.55,1.49$ & .698 & 0.65 & 1.91 & $1.12,3.26$ & .018 \\
\hline Parental divorce & -0.09 & 0.91 & $0.64,1.30$ & .605 & -0.27 & 0.76 & $0.46,1.24$ & .277 & 0.31 & 1.37 & $0.79,2.37$ & .266 \\
\hline Nagelkerke pseudo $\mathrm{R}^{2}$ & \multicolumn{4}{|c|}{.215} & \multicolumn{4}{|c|}{.232} & \multicolumn{4}{|c|}{.234} \\
\hline Cox \& Snell $\mathrm{R}^{2}$ & \multicolumn{4}{|c|}{.145} & \multicolumn{4}{|c|}{.161} & \multicolumn{4}{|c|}{.152} \\
\hline Hosmer-Lemeshow GOF test (sig.) & \multicolumn{4}{|c|}{$5.86(.663)$} & \multicolumn{4}{|c|}{$3.25(.918)$} & \multicolumn{4}{|c|}{$8.62(.375)$} \\
\hline Overall percentage correctly classified & \multicolumn{4}{|c|}{76.8} & \multicolumn{4}{|c|}{75.8} & \multicolumn{4}{|c|}{79.8} \\
\hline
\end{tabular}

$\beta$ beta value, $a O R$ adjusted odds ratio, $C I$ Confidence Interval, GOF goodness of fit; statistically significant results are in bold face

\section{Factors Associated with Suicidal Ideation}

This study has shown that more female than male adolescents reported personal lifestyle problems and interpersonal adversities mainly outside the family circle; compared with males, females who experienced personal lifestyle problems and interpersonal adversities were more likely to report suicidal ideation. Specifically, relative to boys, girls are more likely to experience the negative effects of polygamous families, including poor schoolwork, corporal punishment, and poverty (Al-Sharfi, Pfeffer, \& Miller, 2016); and shortly after a romantic breakup, girls are more likely to experience suicidal ideation (Paul, 2018). Evidence from Ghana suggests that, predominantly, girls (than boys) are more vulnerable to various forms of sexual abuse (Quarshie, Osafo, Akotia, Peprah, \& Andoh-Arthur, 2017; Quarshie et al., 2018); thus, it is not surprising that the current study suggests that sexual abuse victimisation is a strong associated factor of suicidal ideation among girls. The evidence that schoolwork problems is associated with suicidal ideation is to be expected, as evidence from Ghana suggests that teachers and parents tend to place high academic performance expectations on their wards (Ansong, Okumu, Bowen, Walker, \& Eisensmith, 2017); a situation which often results in test anxiety - which in turn leads to poor exam performance among students. Poor schoolwork tends to increase the risk of self-harm and suicidal behaviour in young people (Evans \& Hurrell, 2016). Put together, these findings may be pointing to the general psychosocial 
difficulties experienced mostly by girls in low-resource contexts, particularly, rural communities within Africa where compared to boys and men - girls and women are at increased vulnerability to social exclusion and discrimination, unsupportive cultural norms, and multiple psychosocial challenges (Kabiru, 2015; Kabiru et al., 2013).

The evidence that conflict with parents was strongly associated with suicidal ideation among males was counterintuitive and unexpected. Future studies could explore plausible explanations for this association among boys. However, the extant literature suggests that self-derogation and self-blame mediate the association between parent-adolescent conflict and adolescent suicidal ideation (Shagle \& Barber, 1993). In this context, adolescent suicidal ideation may serve the purpose of escaping or avoiding the self-derogation and selfblame experience resulting from the conflict with parents (Shagle \& Barber, 1993). Perhaps, future studies using robust designs - including carefully planned qualitative approaches could explore this possible explanation of suicidal ideation as a 'coping mechanism' resulting from parent-adolescent conflict.

Consistent with the global literature, regardless of gender, rural adolescents in the current study who reported being exposed to a friend's suicide attempt were about three times more likely to report suicidal ideation (Hill et al., 2020; Insel \& Gould, 2008; Jarvi, Jackson, Swenson, \& Crawford, 2013). Although a worrying situation, the direct exposure to or witnessing or having knowledge of a friend's attempt at suicide to manage distress could serve as a model for adolescent peers experiencing challenging circumstances.

The finding that older adolescence is associated with reduced odds of suicidal ideation could be consistent with the evidence of longitudinal studies that self-harm and suicidal behaviour peak in adolescence, around mid-ages 15-16 years, and reduce towards late-ages 18-19 years to early adulthood (Plener, Schumacher, Munz, \& Groschwitz, 2015). The natural challenges of interpersonal difficulties and increased risky health related behaviours - including alcohol and substance misuse - during early adolescence could be responsible for the increased odds of suicidal ideation among younger adolescents (Hawton et al., 2012; Viner et al., 2012).

An unexpected finding of the present study is the significant association of alcohol with suicidal ideation among females (the association did not reach the desired statistical threshold among males), although more males (23.8\%) than females $(21.4 \%)$ reported alcohol use. This is surprising because previous studies from Ghana have consistently shown higher estimates of alcohol use among adolescent males than females (Adu-Mireku, 2003; Asante \& Kugbey, 2019). Considering that this is the first study from rural Ghana, further studies are needed to clarify this association. While it is possible that the association between alcohol use and suicidal ideation may be stronger among female than male adolescents in rural Ghana, the weaker association observed among males in this study could be due to underpowered male sample size in the analysis. Beyond these possibilities, the evidence underscores the need for government to strengthen the enforcement of the country's alcohol policy to prevent access and sale of alcoholic beverages to underage persons (Ministry of Health Ghana, 2016). A recent systematic review suggests that strengthening policies targeted at reducing harmful alcohol consumption could contribute to reducing suicidal behaviours (Kõlves et al., 2020).

Clearly, several unexpected findings of the current study will benefit from future research towards expanding our understanding of suicidal behaviours among rural-dwelling adolescents in Ghana. For example, the global and regional literature is replete with evidence to suggest that bullying victimisation, parental divorce, and truancy are strongly associated with escalated risk of suicidal behaviours among school-going young people (Asante et al., 2017; Evans, Hawton, \& Rodham, 2004; Fuller-Thomson \& Dalton, 2011; Wagner, Silverman, \& Martin, 2003; Wilson, Dunlavy, Viswanathan, \& Bovet, 2012); however, the current study found no statistically significant associations between these factors and suicidal ideation. While these factors exist in families, schools, and among students in Ghana, we strongly suspect that the variables were underpowered in the analysis of our study.

\section{Implications and Recommendations}

The evidence of this study supports the socio-ecological framework of suicidal behaviour among adolescents, due to the interrelated and multi-level nature of the associated factors (Ayyash-Abdo, 2002; Perkins \& Hartless, 2002; Shagle \& Barber, 1995; WHO, 2014). This implies that intervention, prevention and health promotion programmes should be designed and approached holistically - to include the individual adolescent, their school, family, and other contexts outside the family and school (Perkins \& Hartless, 2002; Quarshie \& Andoh-Arthur, 2020; WHO, 2014). At the population level, this study supports recommendations by recent studies that the Ministry of Education and the Ghana Education Service should consider developing and adopting an adolescent mental health policy, and assessment and management protocols to support students who may be (at risk of) engaging in suicidal behaviour (Asante et al., 2017; Baiden et al., 2019; Quarshie \& Andoh-Arthur, 2020; Quarshie, Waterman, \& House, 2020a, b). At the local and individual level, social skills, stress management and problem-solving skills programmes for in-school adolescents could be helpful in encouraging help-seeking and preventing suicidal behaviour among adolescents. Rural schools, local communities, parent-teacher groups, and families could consider working together towards providing social support to adolescents, 
encouraging parent-child dialogue to resolve family conflict, and clamping down on sexual abuse of children and adolescents. Potentially, these school-community-family collaborations could culminate in supportive family climate, healthpromoting school environment, and enhanced adolescent (mental) wellbeing.

\section{Strengths and Limitations}

This study is partly in response to the call by the most recent systematic reviews for expansive studies on self-harm and suicidal behaviour among young people in sub-Saharan Africa (Aggarwal et al., 2017; Lim et al., 2019; Quarshie, Waterman, \& House, 2020c). This study represents the first attempt from Ghana to provide systematic evidence on the prevalence of suicidal ideation and some personal and interpersonal correlates among rural in-school adolescents. Nonetheless, some plausible limitations of the study are noteworthy. Given that suicidal behaviour is criminalised and stigmatised in Ghana (Osafo, Akotia, Andoh-Arthur, \& Quarshie, 2015), it is possible that our participants might have provided socially desirable and guarded responses to questions related to suicidal thoughts and acts. However, we believe that social desirability bias might be minimal in this study, as participants were allowed enough privacy in responding to the survey - we used an anonymous selfreport questionnaire, participants sat far apart from one another, and teachers were kept in the background, during the survey. It is also notable that the cross-sectional design used does not allow for causal interpretation of our findings.

Furthermore, our study failed to include absentees and out-of-school rural-dwelling adolescents. This implies that whereas our findings may be applied to non-clinical inschool adolescents in rural Eastern Ghana (and, possibly, other rural contexts of the country), it may not be necessarily generalisable across their peers who are out-ofschool. Our study also failed to consider some known potential covariates of suicidal ideation among adolescents, for example, personality, depression, anxiety, among other personal, family, and locality factors (Kinyanda et al., 2011; Nyundo et al., 2020; Rudatsikira et al., 2007; Shilubane et al., 2014). Also, longitudinal studies using robust designs are needed to understand the risks and protective factors, and patterns of suicidal ideation across adolescence in rural Ghana. Lastly, in keeping with recent recommendations regarding adolescent suicidal behaviour research in sub-Saharan Africa (Quarshie, Waterman, \& House, 2020a, c), future studies could employ qualitative methods to explore the individualised, gender-specific, and shared meanings and motivations of rural adolescents who report suicidal ideations - the findings may be informative for (targeted) intervention and prevention programmes (White, Marsh, Kral, \& Morris, 2016).

\section{Conclusion}

Overall, $25.1 \%$ participants $(95 \% \mathrm{CI}=22.5-27.7)$, representing $28.3 \%$ females $(95 \% \mathrm{CI}=24.7-32.2)$ and $21.5 \%$ males $(95 \% \mathrm{CI}=18.0-25.2)$ reported suicidal ideation during the previous 12 months. The prevalence of suicidal ideation among adolescents in rural Ghana compares with estimates among school-going adolescents from other countries within sub-Saharan Africa, but also underscores the need for targeted and universal prevention programmes and intervention efforts to mitigate the potential transition from suicidal ideation to suicidal attempt and eventual suicide among adolescents in rural Ghana.

Supplementary Information The online version contains supplementary material available at https://doi.org/10.1007/s12144-021-01378-3.

Acknowledgements We wish to thank the Ayensuano District Educational Directorate and heads of all the participating schools who granted permissions for this study. We also thank parents and guardians who consented for their underage wards to participate in this study. Finally, we thank all the students who participated in this study to contribute data about their suicidal behaviour for this study.

Author Contributions ENBQ and SKO contributed to the study concept and design; ENBQ performed statistical analysis of the data; SKO and ENBQ drafted the manuscript and critiqued the manuscript for important intellectual content. All the authors contributed to the interpretation of results and revision of the manuscript and approved the final version. ENBQ serves as guarantor for the contents of this paper.

Data Availability The datasets used and/or analysed during the current study are available from the corresponding author on reasonable request.

\section{Declarations}

Conflict of Interest The author(s) declared no potential conflicts of interest with respect to the research, authorship, and/or publication of this article.

Open Access This article is licensed under a Creative Commons Attribution 4.0 International License, which permits use, sharing, adaptation, distribution and reproduction in any medium or format, as long as you give appropriate credit to the original author(s) and the source, provide a link to the Creative Commons licence, and indicate if changes were made. The images or other third party material in this article are included in the article's Creative Commons licence, unless indicated otherwise in a credit line to the material. If material is not included in the article's Creative Commons licence and your intended use is not permitted by statutory regulation or exceeds the permitted use, you will need to obtain permission directly from the copyright holder. To view a copy of this licence, visit http://creativecommons.org/licenses/by/4.0/. 


\section{References}

Adjorlolo, S., Anum, A., \& Amin, J. M. (2020). Validation of the suicidal behaviors questionnaire-revised in adolescents in Ghana. Journal of Mental Health (ahead-of-issue). https://doi.org/10.1080/09638237. 2020.1739239.

Adu-Mireku, S. (2003). The prevalence of alcohol, cigarette, and marijuana use among Ghanaian senior secondary students in an urban setting. Journal of Ethnicity in Substance Abuse, 2(1), 53-65. https://doi.org/10.1300/J233v02n01_05.

Aggarwal, S., Patton, G., Reavley, N., Sreenivasan, S. A., \& Berk, M. (2017). Youth self-harm in low-and middle-income countries: Systematic review of the risk and protective factors. International Journal of Social Psychiatry, 63(4), 359-375. https://doi.org/10. 1177/0020764017700175.

Al-Sharfi, M., Pfeffer, K., \& Miller, K. A. (2016). The effects of polygamy on children and adolescents: A systematic review. Journal of Family Studies, 22(3), 272-286. https://doi.org/10.1080/13229400. 2015.1086405.

Ansong, D., Okumu, M., Bowen, G. L., Walker, A. M., \& Eisensmith, S. R. (2017). The role of parent, classmate, and teacher support in student engagement: Evidence from Ghana. International Journal of Educational Development, 54, 51-58. https://doi.org/10.1016/j. ijedudev.2017.03.010.

Asante, K. O., \& Kugbey, N. (2019). Alcohol use by school-going adolescents in Ghana: Prevalence and correlates. Mental Health \& Prevention, 13, 75-81. https://doi.org/10.1016/j.mhp.2019.01.009.

Asante, K. O., Kugbey, N., Osafo, J., Quarshie, E. N.-B., \& Sarfo, J. O. (2017). The prevalence and correlates of suicidal behaviours (ideation, plan and attempt) among adolescents in senior high schools in Ghana. SSM-Population Health, 3, 427-434. https://doi.org/10. 1016/j.ssmph.2017.05.005.

Ayyash-Abdo, H. (2002). Adolescent suicide: An ecological approach. Psychology in the Schools, 39(4), 459-475. https://doi.org/10.1002/ pits. 10042 .

Babyak, M. A. (2004). What you see may not be what you get: A brief, nontechnical introduction to overfitting in regression-type models. Psychosomatic Medicine, 66(3), 411-421. https://doi.org/10.1097/ 01.psy.0000127692.23278.a9.

Baiden, P., Kuuire, V. Z., Shrestha, N., Tonui, B. C., Dako-Gyeke, M., \& Peters, K. K. (2019). Bullying victimization as a predictor of suicidal ideation and suicide attempt among senior high school students in Ghana: Results from the 2012 Ghana global school-based health survey. Journal of School Violence, 18(2), 300-317. https://doi. org/10.1080/15388220.2018.1486200.

Centers for Disease Control and Prevention (2019). The social-ecological model: A framework for prevention. https://www.cdc.gov/ violenceprevention/publichealthissue/social-ecologicalmodel.html.

Cha, C. B., Franz, P. J., Guzmán, M. E., Glenn, C. R., Kleiman, E. M., \& Nock, M. K. (2018). Annual research review: Suicide among youthepidemiology,(potential) etiology, and treatment. Journal of Child Psychology and Psychiatry, 59(4), 460-482. https://doi.org/10. 1111/jcpp.12831.

Cochran, W. G. (1963). Sampling techniques (2nd ed.). Hoboken: Wiley.

Crosby, A. E., Ortega, L., \& Melanson, C. (2011). Self-directed violence surveillance: uniform definitions and recommended data elements, Version 1.0. Centers for Disease Control and Prevention, National Center for Injury Prevention and Control - Division of Violence Prevention.

Evans, E., Hawton, K., \& Rodham, K. (2004). Factors associated with suicidal phenomena in adolescents: A systematic review of population-based studies. Clinical Psychology Review, 24(8), 957979. https://doi.org/10.1016/j.cpr.2004.04.005.

Evans, R., \& Hurrell, C. (2016). The role of schools in children and young people's self-harm and suicide: Systematic review and meta- ethnography of qualitative research. BMC Public Health, 16(1), 401. https://doi.org/10.1186/s12889-016-3065-2.

Franklin, J. C., Ribeiro, J. D., Fox, K. R., Bentley, K. H., Kleiman, E. M., Huang, X., Musacchio, K. M., Jaroszewski, A. C., Chang, B. P., \& Nock, M. K. (2017). Risk factors for suicidal thoughts and behaviors: A meta-analysis of 50 years of research. Psychological Bulletin, 143(2), 187-232. https://doi.org/10.1037/bul0000084.

Fuller-Thomson, E., \& Dalton, A. D. (2011). Suicidal ideation among individuals whose parents have divorced: Findings from a representative Canadian community survey. Psychiatry Research, 187(1-2), 150-155. https://doi.org/10.1016/j.psychres.2010.12.004.

Ghana Statistical Service. (2014). 2010 population and housing census. District analytical report: Ayensuano distrisct. Ghana Statistical Service.

Ghana Statistical Service - GSS. (2013). 2010 population \& housing census report. Regional analytical report: Greater Accra Region.

Glenn, C. R., Kleiman, E. M., Kellerman, J., Pollak, O., Cha, C. B., Esposito, E. C., Porter, A. C., Wyman, P. A., \& Boatman, A. E. (2020). Annual research review: A meta-analytic review of worldwide suicide rates in adolescents. Journal of Child Psychology and Psychiatry, 61(3), 294-308. https://doi.org/10.1111/jcpp.13106.

Graham, J. W. (2012). Missing data: Analysis and design. Berlin: Springer.

Hawton, K., Saunders, K. E., \& O'Connor, R. C. (2012). Self-harm and suicide in adolescents. The Lancet, 379(9834), 2373-2382. https:// doi.org/10.1016/S0140-6736(12)60322-5.

Hill, N. T., Robinson, J., Pirkis, J., Andriessen, K., Krysinska, K., Payne, A., Boland, A., Clarke, A., Milner, A., \& Witt, K. (2020). Association of suicidal behavior with exposure to suicide and suicide attempt: A systematic review and multilevel meta-analysis. PLoS Medicine, 17(3), e1003074. https://doi.org/10.1371/journal. pmed.1003074.

Hirsch, J. K. (2006). A review of the literature on rural suicide. Crisis, 27(4), 189-199. https://doi.org/10.1027/0227-5910.27.4.189.

Hirsch, J. K., \& Cukrowicz, K. C. (2014). Suicide in rural areas: An updated review of the literature. Journal of Rural Mental Health, 38(2), 65-78. https://doi.org/10.1037/rmh0000018.

Hom, M. A., Joiner Jr., T. E., \& Bernert, R. A. (2016). Limitations of a single-item assessment of suicide attempt history: Implications for standardized suicide risk assessment. Psychological Assessment, 28(8), 1026-1030. https://doi.org/10.1037/pas0000241.

House, A., Kapur, N., \& Knipe, D. (2020). Thinking about suicidal thinking. The Lancet Psychiatry, 7(11), 997-1000. https://doi.org/ 10.1016/S2215-0366(20)30263-7.

Insel, B. J., \& Gould, M. S. (2008). Impact of modeling on adolescent suicidal behavior. Psychiatric Clinics of North America, 31(2), 293 316. https://doi.org/10.1016/j.psc.2008.01.007.

Jarvi, S., Jackson, B., Swenson, L., \& Crawford, H. (2013). The impact of social contagion on non-suicidal self-injury: A review of the literature. Archives of Suicide Research, 17(1), 1-19. https://doi.org/10. 1080/13811118.2013.748404.

Kabiru, C. (2015). Adolescent girls' well-being in resource-poor settings. UNICEF. https://www.unicef-irc.org/article/1150-adolescent-girlswell-being-in-resource-poor-settings.html. Accessed 13 Dec 2019.

Kabiru, C. W., Izugbara, C. O., \& Beguy, D. (2013). The health and wellbeing of young people in sub-Saharan Africa: An underresearched area? BMC International Health and Human Rights, 13(1), 11. https://doi.org/10.1186/1472-698x-13-11.

Kabiru, C. W., Undie, C., \& Ezeh, A. C. (2011). A generation at risk: Prioritizing child and youth health. In R. Parker \& M. Sommer (Eds.), Routledge Handbook of Global Public Health (pp. 182190). Abingdon: Routledge.

Kelleher, K. J., Taylor, J. L., \& Rickert, V. I. (1992). Mental health services for rural children and adolescents. Clinical Psychology Review, 12(8), 841-852. https://doi.org/10.1016/0272-7358(92) 90005-S 
Kinyanda, E., Kizza, R., Levin, J., Ndyanabangi, S., \& Abbo, C. (2011). Adolescent suicidality as seen in rural northeastern Uganda. Crisis, 32(1), 43-51. https://doi.org/10.1027/0227-5910/a000059.

Klonsky, E. D., May, A. M., \& Saffer, B. Y. (2016). Suicide, suicide attempts, and suicidal ideation. Annual Review of Clinical Psychology, 12, 307-330. https://doi.org/10.1146/annurev-clinpsy021815-093204.

Koenig, H. G., \& Büssing, A. (2010). The Duke University religion index (DUREL): A five-item measure for use in epidemological studies. Religions, 1(1), 78-85. https://doi.org/10.3390/rel1010078.

Kõlves, K., Chitty, K. M., Wardhani, R., Värnik, A., De Leo, D., \& Witt, K. (2020). Impact of alcohol policies on suicidal behavior: A systematic literature review. International Journal of Environmental Research and Public Health, 17(19), 7030. https://doi.org/10. 3390/ijerph17197030.

Lim, K.-S., Wong, C. H., McIntyre, R. S., Wang, J., Zhang, Z., Tran, B. X., Tan, W., Ho, C. S., \& Ho, R. C. (2019). Global lifetime and 12month prevalence of suicidal behavior, deliberate self-harm and non-suicidal self-injury in children and adolescents between 1989 and 2018: A meta-analysis. International Journal of Environmental Research and Public Health, 16(22), 4581. https://doi.org/10.3390/ ijerph16224581.

McKinnon, B., Gariépy, G., Sentenac, M., \& Elgar, F. J. (2016). Adolescent suicidal behaviours in 32 low-and middle-income countries. Bulletin of the World Health Organization, 94(5), 340-350F. https://doi.org/10.2471/BLT.15.163295.

Millner, A. J., Lee, M. D., \& Nock, M. K. (2015). Single-item measurement of suicidal behaviors: Validity and consequences of misclassification. PLoS One, 10(10), e0141606. https://doi.org/10.1371/ journal.pone. 0141606 .

Ministry of Health Ghana. (2016). Republic of Ghana national alcohol policy. Accra, Ghana: Ministry of Health, WHO, Baraka Policy Institute.

Naghavi, M., \& Global Burden of Disease Self-Harm Collaborators. (2019). Global, regional, and national burden of suicide mortality 1990 to 2016: Systematic analysis for the global burden of disease study 2016. BMJ, 364, 194. https://doi.org/10.1136/bmj.194.

Naing, L., Winn, T., \& Rusli, B. (2006). Practical issues in calculating the sample size for prevalence studies. Archives of Orofacial Sciences, $1,9-14$.

Nock, M. K. (2012). Future directions for the study of suicide and selfinjury. Journal of Clinical Child \& Adolescent Psychology, 41(2), 255-259. https://doi.org/10.1080/15374416.2012.652001.

Nyundo, A., Manu, A., Regan, M., Ismail, A., Chukwu, A., Dessie, Y., Njau, T., Kaaya, S. F., \& Smith Fawzi, M. C. (2020). Factors associated with depressive symptoms and suicidal ideation and behaviours amongst sub-Saharan African adolescents aged 10-19 years: Cross-sectional study. Tropical Medicine \& International Health, 25(1), 54-69. https://doi.org/10.1111/tmi.13336.

Odame, S. K., Quarshie, E. N.-B., Oti-Boadi, M., Andoh-Arthur, J., \& Asante, K. O. (2020). Adolescent problem gambling in rural Ghana: Prevalence and gender differentiation. Journal of gambling studies(advance online publication), 1-23. https://doi.org/10.1007/s10899020-09987-6.

Ohene, S.-A., Johnson, K., Atunah-Jay, S., Owusu, A., \& Borowsky, I. W. (2015). Sexual and physical violence victimization among senior high school students in Ghana: Risk and protective factors. Social Science \& Medicine, 146, 266-275. https://doi.org/10.1016/j. socscimed.2015.10.019.

Osafo, J., Akotia, C. S., Andoh-Arthur, J., \& Quarshie, E. N.-B. (2015). Attempted suicide in Ghana: Motivation, stigma, and coping. Death Studies, 39(5), 274-280. https://doi.org/10.1080/07481187.2014. 991955.

Osman, A., Bagge, C. L., Gutierrez, P. M., Konick, L. C., Kopper, B. A., \& Barrios, F. X. (2001). The suicidal behaviors questionnairerevised (SBQ-R): Validation with clinical and nonclinical samples.
Assessment, 8(4), 443-454. https://doi.org/10.1177/ 107319110100800409.

Owusu, A. (2012). Global school-based student health survey (GSHS): Ghana report. Middle Tennessee State University, Ghana Education Service, \& WHO.

Owusu, A., Hart, P., Oliver, B., \& Kang, M. (2011). The association between bullying and psychological health among senior high school students in Ghana, West Africa. Journal of School Health, 81(5), 231-238. https://doi.org/10.1111/j.1746-1561.2011.00590.x.

Page, R. M., \& West, J. H. (2011). Suicide ideation and psychosocial distress in sub-Saharan African youth. American Journal of Health Behavior, 35(2), 129-141. https://doi.org/10.5993/ajhb.35.2.1.

Paul, E. (2018). Proximally-occurring life events and the first transition from suicidal ideation to suicide attempt in adolescents. Journal of Affective Disorders, 241, 499-504. https://doi.org/10.1016/j.jad. 2018.08.059.

Perkins, D. F., \& Hartless, G. (2002). An ecological risk-factor examination of suicide ideation and behavior of adolescents. Journal of Adolescent Research, 17(1), 3-26. https://doi.org/10.1177/ 0743558402171001

Pfledderer, C. D., Burns, R. D., \& Brusseau, T. A. (2019). School environment, physical activity, and sleep as predictors of suicidal ideation in adolescents: Evidence from a national survey. Journal of Adolescence, 74, 83-90. https://doi.org/10.1016/j.adolescence. 2019.05.008.

Plener, P. L., Schumacher, T. S., Munz, L. M., \& Groschwitz, R. C. (2015). The longitudinal course of non-suicidal self-injury and deliberate self-harm: A systematic review of the literature. Borderline Personality Disorder and Emotion Dysregulation, 2(1), 2. https:// doi.org/10.1186/s40479-014-0024-3.

Prematunga, R. K. (2012). Correlational analysis. Australian Critical Care, 25(3), 195-199. https://doi.org/10.1016/j.aucc.2012.02.003.

Quarshie, E. N.-B., \& Andoh-Arthur, J. (2020). Suicide attempts among 1437 adolescents aged 12-17 years attending junior high schools in Ghana. Crisis(advance online publication), 1-10. https://doi.org/10. 1027/0227-5910/a000746.

Quarshie, E. N. B., Cheataa-Plange, H. V., Annor, F., Asare-Doku, W., \& Lartey, J. K. S. (2019). Prevalence of suicidal behaviour among nursing and midwifery college students in Ghana. Nursing Open, 6, 897-906. https://doi.org/10.1002/nop2.271.

Quarshie, E. N.-B., Davies, P. A., Ivanna, M., Badasu, A., Tagoe, T., Otoo, P. A., \& Afriyie, P. O. (2018). Multiple perpetrator rape in Ghana: Offenders, victims and offence characteristics. Journal of Sexual Aggression, 24(1), 125-141. https://doi.org/10.1080/ 13552600.2017.1378024.

Quarshie, E. N.-B., Odame, S. K., \& Annor, F. (2020). Suicidal behavior in the Ghana police service. Prevalence and coreelates in the Greater Accra Region. Crisis(ahead-of-issue). https://doi.org/10.1027/02275910/a000707.

Quarshie, E. N.-B., Osafo, J., Akotia, C. S., Peprah, J., \& Andoh-Arthur, J. (2017). Some epidemiological characteristics of perpetrators and victims of incest in contemporary Ghana: Analysis of media reports. Journal of Child Sexual Abuse, 26(2), 121-139. https://doi.org/10. 1080/10538712.2016.1277573.

Quarshie, E. N.-B., Waterman, M. G., \& House, A. O. (2020a). Adolescent self-harm in Ghana: A qualitative interview-based study of first-hand accounts. BMC Psychiatry, 20(275), 275. https://doi. org/10.1186/s12888-020-02599-9.

Quarshie, E. N.-B., Waterman, M. G., \& House, A. O. (2020b). Adolescents at risk of self-harm in Ghana: A qualitative interview study exploring the views and experiences of key adult informants. BMC Psychiatry, 20(310), 310. https://doi.org/10.1186/s12888020-02718-6.

Quarshie, E. N.-B., Waterman, M. G., \& House, A. O. (2020c). Self-harm with suicidal and non-suicidal intent in young people in sub-Saharan 
Africa: A systematic review. BMC Psychiatry, 20(234), 1-26. https://doi.org/10.1186/s12888-020-02587-z.

Rudatsikira, E., Muula, A. S., Siziya, S., \& Twa-Twa, J. (2007). Suicidal ideation and associated factors among school-going adolescents in rural Uganda. BMC Psychiatry, 7(1), 67. https://doi.org/10.1186/ 1471-244X-7-67.

Shagle, S. C., \& Barber, B. K. (1993). Effects of family, marital, and parent-child conflict on adolescent self-derogation and suicidal ideation. Journal of Marriage and the Family, 55(4), 964-974. https:// doi.org/10.2307/352776

Shagle, S. C., \& Barber, B. K. (1995). A social-ecological analysis of adolescent suicidal ideation. American Journal of Orthopsychiatry, 65(1), 114-124. https://doi.org/10.1037/h0079591.

Shilubane, H. N., Ruiter, R. A., Bos, A. E., van den Borne, B., James, S., \& Reddy, P. S. (2014). Psychosocial correlates of suicidal ideation in rural south African adolescents. Child Psychiatry \& Human Development, 45(2), 153-162. https://doi.org/10.1007/s10578013-0387-5.

Sun, G.-W., Shook, T. L., \& Kay, G. L. (1996). Inappropriate use of bivariable analysis to screen risk factors for use in multivariable analysis. Journal of Clinical Epidemiology, 49(8), 907-916. https://doi.org/10.1016/0895-4356(96)00025-X.

Turecki, G., Brent, D. A., Gunnell, D., O'Connor, R. C., Oquendo, M. A., Pirkis, J., \& Stanley, B. H. (2019). Suicide and suicide risk. Nature Reviews. Disease Primers, 5(1), 1-22. https://doi.org/10.1038/ s41572-019-0121-0.

Uddin, R., Burton, N. W., Maple, M., Khan, S. R., \& Khan, A. (2019). Suicidal ideation, suicide planning, and suicide attempts among adolescents in 59 low-income and middle-income countries: A population-based study. The Lancet Child \& Adolescent Health, 3(4), 223-233. https://doi.org/10.1016/s2352-4642(18)30403-6.

Van Droogenbroeck, F., Spruyt, B., \& Keppens, G. (2018). Gender differences in mental health problems among adolescents and the role of social support: Results from the Belgian health interview surveys 2008 and 2013. BMC Psychiatry, 18(1), 6. https://doi.org/10.1186/ s12888-018-1591-4.

Viner, R. M., Ozer, E. M., Denny, S., Marmot, M., Resnick, M., Fatusi, A., \& Currie, C. (2012). Adolescence and the social determinants of health. The Lancet, 379(9826), 1641-1652. https://doi.org/10.1016/ S0140-6736(12)60149-4.

Von Elm, E., Altman, D. G., Egger, M., Pocock, S. J., Gøtzsche, P. C., \& Vandenbroucke, J. P. (2007). The strengthening the reporting of observational studies in epidemiology (STROBE) statement: Guidelines for reporting observational studies. Annals of Internal Medicine, 147(8), 573-577. https://doi.org/10.7326/0003-4819147-8-200710160-00010.

Wagner, B. M., Silverman, M. A. C., \& Martin, C. E. (2003). Family factors in youth suicidal behaviors. American Behavioral Scientist, 46(9), 1171-1191. https://doi.org/10.1177/0002764202250661.

White, J., Marsh, I., Kral, M. J., \& Morris, J. (Eds.). (2016). Critical suicidology: Transforming suicide research and prevention for the 21st century. Vancouver, Canada: University of British Columbia Press (UBC) Press.

WHO. (2014). Preventing suicide: A global imperative. WHO.

Wilson, M. L., Dunlavy, A. C., Viswanathan, B., \& Bovet, P. (2012). Suicidal expression among school-attending adolescents in a middle-income sub-Saharan country. International Journal of Environmental Research and Public Health, 9(11), 4122-4134. https://doi.org/10.3390/ijerph9114122.

Publisher's Note Springer Nature remains neutral with regard to jurisdictional claims in published maps and institutional affiliations. 